EGU21-12955

https://doi.org/10.5194/egusphere-egu21-12955

EGU General Assembly 2021

(c) Author(s) 2022. This work is distributed under

the Creative Commons Attribution 4.0 License.

\title{
Did the Pleistocene tectonics in the Alboran Sea change the distribution and origin of submarine landslides?
}

\author{
Manfred Lafosse ${ }^{1}$, Elia d'Acremont ${ }^{1}$, Sara Lafuerza ${ }^{1}$, Alain Rabaute ${ }^{1}$, Martin Jollivet-Castelot ${ }^{1}$, \\ Belén Alonso ${ }^{2}$, Gemma Ercilla ${ }^{2}$, Juan-Tomas Vazquez ${ }^{3}$, and Christian Gorini \\ ${ }^{1}$ Sorbonne Université, CNRS-INSU, Institut des Sciences de la Terre Paris, ISTeP, F-75005 Paris, France \\ ${ }^{2}$ Instituto de Ciencias del Mar, CSIC, 08003 Barcelona, Spain \\ ${ }^{3}$ Instituto Español de Oceanografía (IEO), C.O. Málaga, 29640 Fuengirola, Málaga, Spain
}

The tectonics of the Alboran Sea control the distribution of topographic highs and depressions, influencing the water masses' paths controlling the deep basins sedimentation rates. Altogether tectonics and deep currents shaped the seafloor on which we map active faults, contourites, pockmarks, and submarine landslides. Recent numerical models highlight that some of those landslides can generate tsunamis waves on nearby coastal areas, creating the need to describe better and understand those seabed features. Consequently, we put together bathymetric and seismic data to measure Pleistocene slides affecting the deep Alboran basin in an unprecedented collective effort.

We mapped and relatively dated 66 mass transport deposits (MTDs) in the West Alboran and Pytheas fields on the north and south flank of the Alboran Ridge. We measured their surfaces, decompacted volumes, slopes, run out, scars heights, scars elevations, and described their type (debris flow or slide) qualitatively from their echo facies. When possible, we also measured the run-off from the scar. We investigated the factor of safety (FOS) and computed based seismic moments based on empirical relationship and faults geometry to characterize the preconditioning factors and triggering mechanisms. The first important result is that post-1.12 Ma MTDs mobilized the most important volumes, in line with the Alboran Sea's topographic highs. Second, seismic lines and the bathymetric images evidence blind reverse faults related to fluid escapes that could contribute to local overpressures in shallow contouritic sediments. Third, we show that local slopes are too flat to allow slopes to destabilize under gravity force only, suggesting that other causal factors need to be considered. Fourth, known seismicity on strike-slip faults in the Alboran Sea is unlikely to trigger MTDs in most investigated areas, suggesting that a combination of preconditioning factors, such as local overpressures and/or reduced strength properties with reverse faults activity, seems the most plausible explanation to trigger the observed MTDs.

The overall results highlight that the Alboran tectonics explain the slope destabilization, with varying local sediment properties. However, those properties and past overpressures, deformations, and fluid flows remain to be locally detailed. Future works involving sediments characterizations and dating will follow after the ALBACORE survey scheduled in 2021. 